\title{
Разведение живого корма для рептилий в домашних условиях
}

\author{
Корниенко Д.С., учащаяся, \\ Информационно-технологический лицей №24, \\ 2. Нерюнгри \\ E-mail: pmaf6363@mail.ru
}

Научный руководитель: учитель биологии Парфенова М.А.

Для успешного содержания террариумных животных важно знать спектр их пищевых предпочтений и иметь возможность обеспечить их адекватными кормами. Многие владельцы рептилий считают более удобным разводить кормовых насекомых, нежели приобретать их в зоомагазинах. Столкнувшись с тем, что порой живой корм бывало просто не достать, мы попробовали сами заняться разведением живого корма. Для разведения были выбраны зофобосы и мучные черви. На практике разведение живого корма оказалось не так просто, как пишут в книжках и на форумах, но методом проб и ошибок мы добились неплохих результатов.

Целью работы является исследование условий развития кормовых насекомых и определение, каких насекомых лучше разводить в домашних условиях.

В ходе достижения цели решались следующие задачи:

1. Изучить литературу о живом корме.

2. Развести кормовых насекомых в домашних условиях.

3. Провести эксперимент и выявить, в каких условиях происходит развитие насекомых и каких насекомых лучше разводить дома.

4. Проанализировать полученный материал.

5. Сделать вывод на основе полученных данных.

Гипотеза: в домашних условиях можно самостоятельно вырастить кормовых насекомых.

Объект исследования: развитие кормовых насекомых в домашних условиях.

Предмет исследования: кормовые насекомые.

Методы исследования: поисковый, сбор информации, практическая деятельность (эксперимент), анализ полученных данных.

\section{Разведение зофобосов и мучных червей}

Зофобосы (часто используется искаженный вариант названия «зоофобус») вид жуков из семейства чернотелки, чьи личинки широко известны под названием зофобас [1, стр. 236].

Зофобос считается наиболее простым в содержании кормовым насекомым. Зофобас разводится при комнатной температуре в пластиковой посуде, заполненной слоем в 3-4 см нехвойной стружки. Для разведения необходимо использовать около 10 жуков разного пола. В качестве корма используются влажные (морковь, капуста) и сухие (геркулес) корма. После появления личинок (внешне напоминающих червячков) жуков требуется отсаживать. Для выведения жуков из крупных личинок последние размещаются по одной в пластиковых контейнерах и помещаются в тёплое влажное место. 
Большой мучной хрущак, или мучной червь, является одним из наиболее популярных и легко разводимых кормовых насекомых. Личинки, взрослые жуки и куколки используются в качестве корма для различных содержащихся в неволе птиц, мелких зверьков, амфибий, рептилий, крупных аквариумных рыб, а также как наживка в рыболовстве [3].

Для разведения мучного червя применяют различные пластиковые, металлические и стеклянные ёмкости. В качестве субстрата используют отруби, овсяные хлопья, сухие каши. Сверху можно положить решётки для яиц, под которыми будут скапливаться насекомые. Субстрат периодически просеивают или заменяют. Насекомых следует периодически подкармливать хлебом, комбикормом для грызунов и рыб, сочными кормами (кусочками яблок, моркови и капусты). Полезно иногда давать животные корма (например, кусочки сырой или варёной рыбы) в качестве белковой добавки. Все влажные корма вносят в садки в ограниченном количестве, удаляя несъеденные остатки. Поилки лучше не применять, так как насекомые не выносят повышенной влажности и легко тонут в воде. Предпочитаемая температура $+23-28{ }^{\circ} \mathrm{C}$. Развитие яиц при температуре $+26-28{ }^{\circ} \mathrm{C}$ длится примерно 2 недели. Личинки растут в течение 4 месяцев. Стадия куколки продолжается 2 недели. Взрослый жук живет 30-45 дней [2, стр. 56].

\section{Исследовательская часть}

Изучив теоретический материал, я приступила к практической части работы. Для этого провела два эксперимента.

\section{Эксперимент №1}

\section{Зависимость развития зофобоса от величины емкости содержания для его}

\section{разведения}

Может ли размер емкости влиять на развитие кормовых насекомых?

Время проведения эксперимента: июль-август 2016 года

Для эксперимента понадобилось 32 червя (зофобоса) и 2 контейнера разных размеров: № 1 - большой, № 2 - маленький. В каждый контейнер помещены по 16 червей с одинаковым количеством кормовой смеси (овсянки) - З5грамм. Личинки содержали в одном месте и питались одинаковой пищей.

Результат. В большом контейнере личинки появились через 30 , a в маленьком - через 40 дней. Количество жуков в большой емкости стало больше, чем в малой, через 50 дней (рис. 1 и 2). 


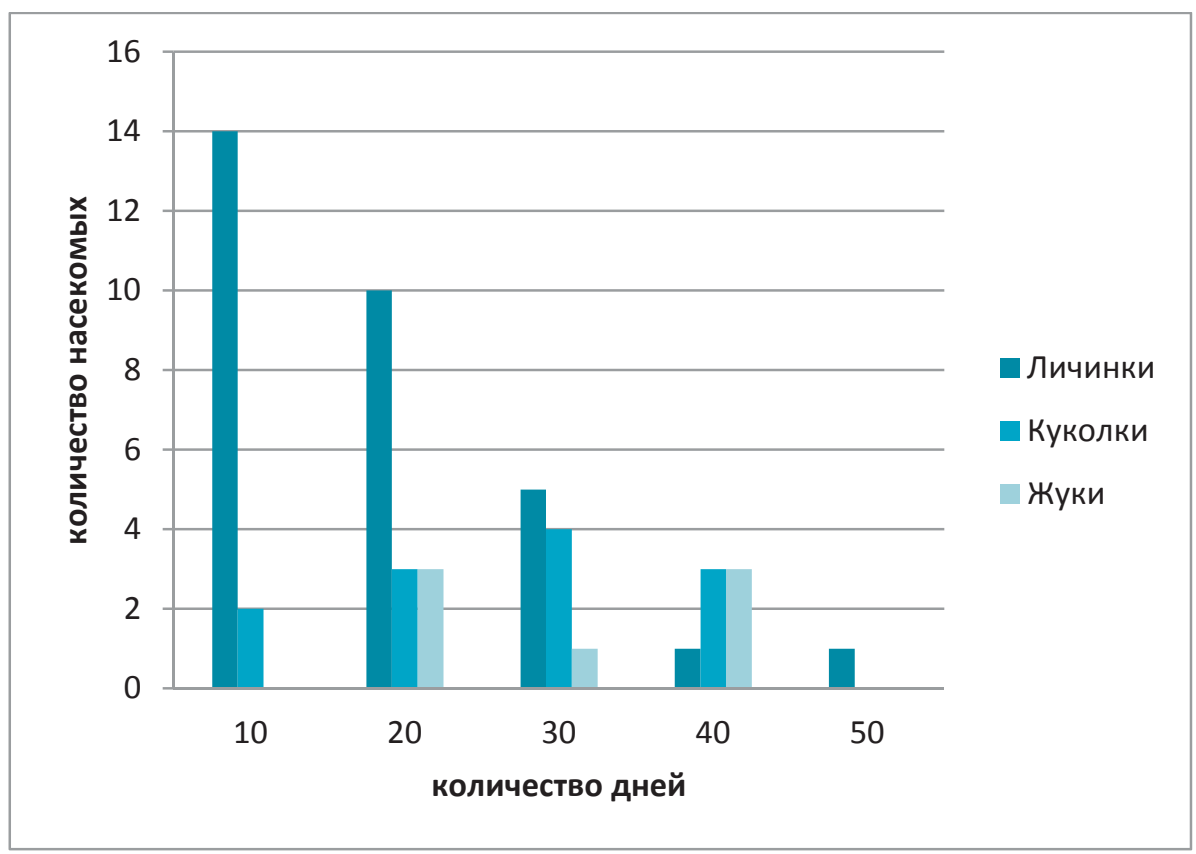

Рис. 1. Развитие зофобаса в контейнере № 1 (большой)

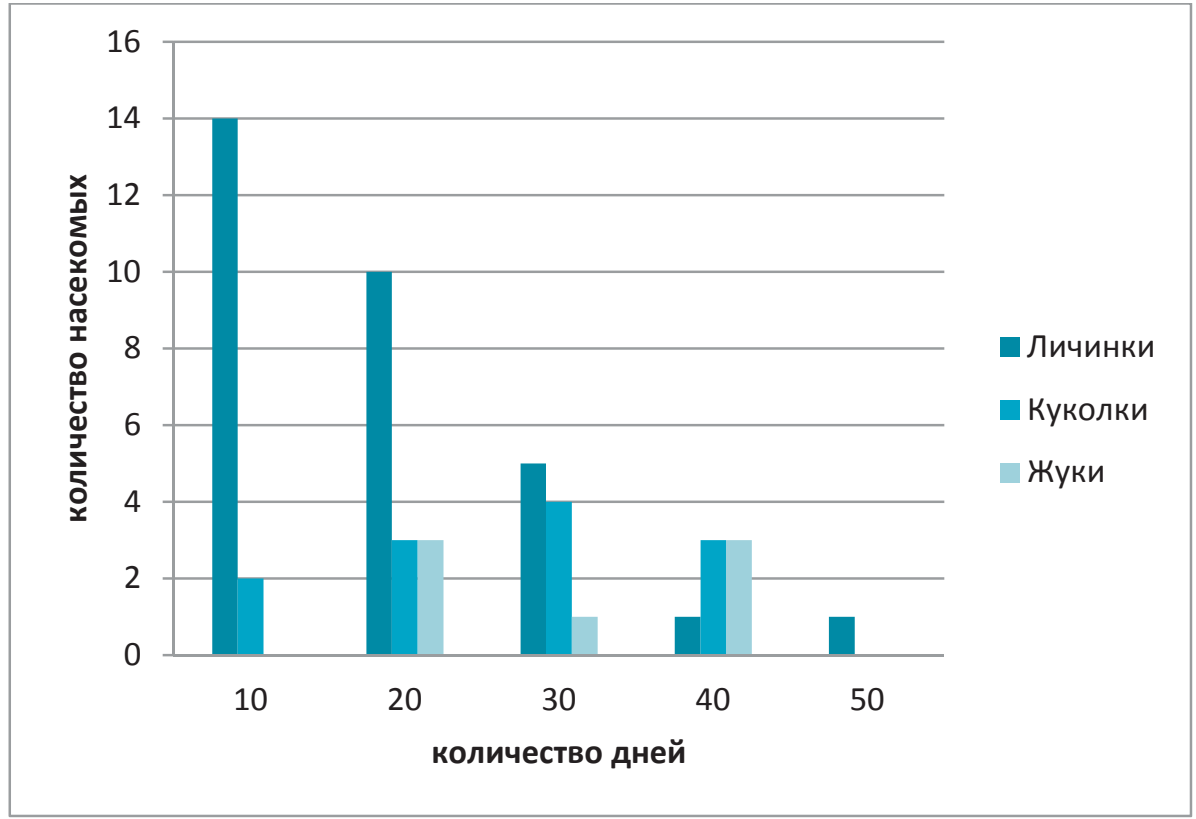

Рис. 2. Развитие зофобаса в контейнере № 2 (маленький)

Вывод. Для содержания зофобосов лучше использовать емкость большого размера.

\section{Эксперимент №2}

\section{Выбор кормовых насекомых для разведения в домашних условиях}

Этот эксперимент был проведен для того, чтобы выбрать, какое кормовое насекомое лучше разводить дома для своего питомца.

Для эксперимента было взято по 16 особей зофобоса и мучного червя и 2 одинаковые емкости. В первую емкость было помещены зофобосы, а во вторую мучные черви. Черви содержались в одинаковых условиях.

Результат. Как видно из рис. 4, через 50 дней колония мучных червей практически вымерла, однако через 3 недели в контейнере снова появились мучники. 
В колонии зофобосов все иначе (рис. 3). У зофобосов очень длинный цикл развития, поэтому за 50 дней в колонии появилось мало насекомых.

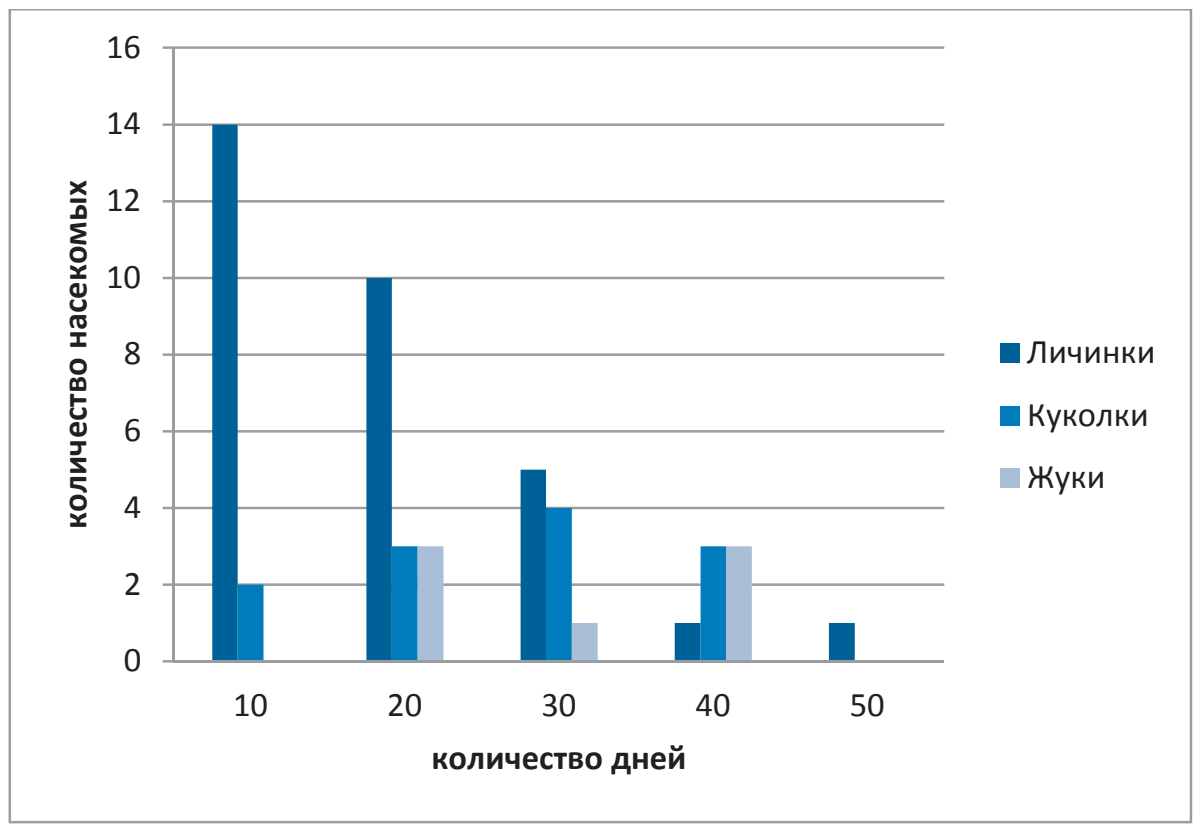

Рис. 3. Развитие зофобаса

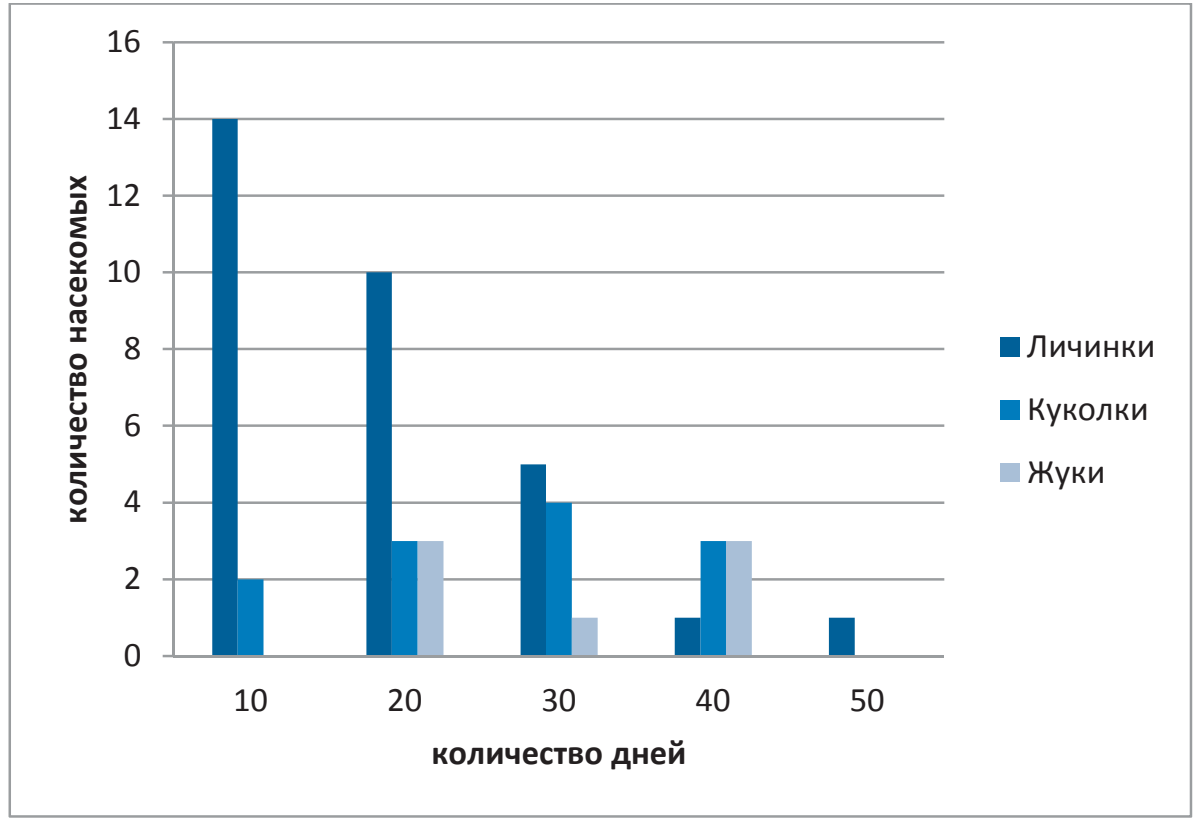

Рис. 4. Развитие мучного червя

Вывод. Если вы новичок и у вас молодая особь рептилий (от 1-го месяца) или если у вас много рептилий, вам подходит мучной червь, поскольку размножение червей происходит быстрее и ими можно кормить часто. Если у вас одна взрослая особь, то вам подходит зофобос, так как развитие зофобоса занимает более длительный период.

\section{Рекомендации по разведению живого корма}

- Для того чтобы вырастить колонию насекомых (зофобоса, мучного червя), нужно купить минимум 10 личинок на разведение - и это с расчетом на то, что вы не будете кормить ими питомца на протяжении 3-4-х месяцев. 
- Правильная подстилка. В качестве подстилки можно использовать овсянку, отруби, или опилки. Ни в коем случае не использовать муку, манку и т.д.

- Правильное питание. Рацион зофобоса состоит из огурцов, яблок и капусты. Огурцами кормить нужно только раз в неделю, одним маленьким кусочком. Если вы будите давать слишком много, тогда в контейнере может появиться плесень или паразиты.

\title{
Заключение
}

В районах Крайнего Севера достаточно сложно содержать экзотических животных-рептилий, если их владелец не научится самостоятельно разводить кормовых насекомых. Кормовых насекомых можно вырастить в домашних условиях, но это достаточно трудоёмкое занятие.

В результате работы сделаны следующие выводы:

1. Для разведения кормовых насекомых нужно использовать большие ёмкости.

2. Для разведения лучше подходят насекомые с большой продолжительностью жизни.

Список литературы:

1. Гиляров М.С. и др. Биологический энциклопедический словарь. М.: Советская энциклопедия, 1986. - 831 с.

2. Кудрявцев С.В. и др. Террариум и его обитатели: Обзор видов и содержание в неволе: Справочное пособие. - М.: Лесн. пром-сть, 1991.

3. Большой мучной хрущак [Электронный ресурс]. - Режим доступа: http://ru.wikipedia.org/wiki/Большой_мучной_хрущак

\section{Биогаз как альтернативное моторное топливо в условиях Севера}

\author{
Кузьмина Р.С., студентка, \\ Северо-Восточный федеральный университет, \\ 2. Якутск \\ E-mail: regiwok95@mail.ru
}

Научный руководитель: старший преподаватель Егорова Е.Н.

В настоящее время на территории Якутии имеется 297 труднодоступных населенных пунктов, где проживают 742500 человек. Всем известно, что в некоторых из этих населенных пунктов отсутствуют автозаправочные станции (АЗС). Это говорит о том, что автовладельцы затрачивают дополнительное расходы для того, чтобы добраться до АЗС.

Сегодня, когда нефтепродукты подорожали, для среднестатистического автовладельца наиболее экономически приемлемым является использование газа в качестве топлива для автомобиля. Также следует учесть, что двигатели внутреннего сгорания (ДВС) своими выбросами загрязняют окружающую среду, но при этом, если двигатель работает на газу, выбросов вдвое, а то и втрое меньше. Путем решения данных проблем послужило бы использование биогазовой технологии утилизации сельскохозяйственных отходов. Внедрение данной технологии позволит решить 